\title{
Synthesis, structural characterization and broadband ferromagnetic resonance in
}

\section{Li ferrite nanoparticles}

P. Hernández-Gómez ${ }^{1 *}$, M. A. Valente ${ }^{2}$, M.P.F. Graça² ${ }^{2}$ J. M. Muñoz ${ }^{1}$

${ }^{1}$ Dpt. Electricidad y Electrónica, Univ. Valladolid, Paseo de Belén 7, 47011 Valladolid Spain

${ }^{2}$ Dpt. Fisica, Univ. Aveiro, Campus de Santiago, Aveiro, Portugal

*Corresponding author

e-mail: pabloher@ee.uva.es

Tel: +34983423895

\begin{abstract}
Lithium ferrites are well known materials due to its numerous technological applications especially in microwave devices. Lithium ferrite nanoparticles were prepared by sol-gel technique by means of Pechini method, and then annealed at different temperatures in $250-1000^{\circ} \mathrm{C}$ range. $\mathrm{XRD}$ confirms spinel formation with particles sizes in 15-700 $\mathrm{nm}$ range, with increased size with annealing temperature, whereas FTIR and Raman measurement confirm that single phase lithium ferrite with ordered cationic structure is obtained. Microwave magnetoabsorption data of the annealed lithium ferrite nanoparticles were obtained with a broadband system based on a network analyzer that operates up to $8.5 \mathrm{GHz}$. At fields up to $200 \mathrm{mT}$ we can observe a broad absorption peak that shifts to higher frequencies with magnetic field according to ferromagnetic resonance theory. The amplitude of absorption, up to $85 \%$, together with the frequency width of about $5.5 \mathrm{GHz}$ makes this material suitable as wave
\end{abstract}


absorber. FMR parameters like resonance field, linewidth and broadening are analyzed in order to obtain the characteristic parameters and analyze the microwave behaviour.

Keywords A. Magnetically ordered materials, A. Nanostructured materials, A. Oxide materials, B. Sol-gel processes, D. Magnetic measurements, D. Ferromagnetic resonance.

\section{Introduction}

Spinel ferrites are still widely used materials in spite of their rather old discovery, and at present they continue to be the focus of intensive research to explore their potential application in new devices, taking profit of their excellent electrical, optical or magnetic properties, as well as the possibility of tailoring them by changing the initial composition or cation substitution [1]. Spinel ferrites are soft magnetic materials with cubic close packed lattice. Among them lithium ferrite $\left(\mathrm{Li}_{0.5} \mathrm{Fe}_{2.5} \mathrm{O}_{4}\right)$, exhibit unique properties as square hysteresis loop, high Curie temperature, moderate saturation magnetization and good thermal stability of their magnetic properties [2, 3]. Due to the absence of divalent iron, it can also be employed in microwave devices, such as circulators, isolators, magnetostatic resonators, filters, switches, limiters and tunable electrooptic modulators, replacing YIG for lower mass production costs [4-6].

Lithium ferrite is a soft ferrimagnetic material with cubic cell crystal lattice with inverse spinel structure in which Li cation occupy octahedral B positions. There are several studies that deal mainly with structural and dielectric properties of Li ferrites [7-10], employing different fabrication techniques different than conventional ceramic technique, because sintering at high temperatures promotes evaporation of lithium that 
made this material technologically difficult to prepare in this way. The sol-gel method provides an easy alternative for the preparation of nanosized lithium ferrites at lower annealing temperatures.

At present, there is an exponential growth in microwave communication through mobile and satellite communications, wireless telecommunications, and electronic and medical measuring equipment in the frequency range up to $8 \mathrm{GHz}$ [11]. In particular $\mathrm{C}$ band contain uplink frequency for satellite telecommunications, ISM band for medical and industrial applications and also the IEEE 802.11a wi-fi system. In order to avoid interference noise, there is strong interest in materials that absorb electromagnetic radiation energy in this band [12]. For broadband operation in L, C or S bands inexpensive, lightweight microwave absorbers are needed, so that magnetic nanoparticles can be used [13]. Regarding metals, the low conductivity of ferrites reduces the skin effect at high frequencies, so that they can attenuate EM waves efficiently in the GHz range. Magnetic field induced microwave absorption in nanoscale ferrites is a recent and active area of research useful in this context [14]. In the present work, broadband microwave magnetoabsorption data of lithium ferrite nanoparticles are presented.

\section{Materials and methods}

\subsection{Sample preparation}

Lithium ferrite nanoparticles were prepared by sol-gel technique by means of Pechini method. Starting materials were $\mathrm{LiNO}_{3}$ (Fluka), $\mathrm{Fe}\left(\mathrm{NO}_{3}\right)_{3} \cdot 9 \mathrm{H}_{2} \mathrm{O}$ (Merck), citric acid ( Sigma Aldrich) and etilenglycol ( Fluka). Molar ratio among $\mathrm{LiNO}_{3}$ and $\mathrm{Fe}\left(\mathrm{NO}_{3}\right)_{3} \cdot 9 \mathrm{H}_{2} \mathrm{O}$ was kept in 1:5, so that spinel ferrite formation is optimized [6]. Molar 
ratio for citric acid: metal was 3:1, and citric acid: etilenglycol was 1:2 In this way, nitrates were solved in distilled water together with citric acid. Solutions were mixed with magnetic stirring for $30 \mathrm{~min}$ at room temperature. Then they were put together, mixed with etilenglycol and stirred for $1 \mathrm{~h}$. to complete esterification reaction. Gel processing was achieved with drying at $90^{\circ} \mathrm{C}$ during $12 \mathrm{~h}$ for water releasing, then $150^{\circ}$ $\mathrm{C}$ during $12 \mathrm{~h}$, and finally $250^{\circ} \mathrm{C}$ during $1 \mathrm{~h}$. Gel volume grows indicating $\mathrm{NO}_{2}, \mathrm{O}_{2}$ and $\mathrm{CO}_{2}$ releasing. Powders thus obtained were annealed at different temperatures in the $400-1000^{\circ} \mathrm{C}$ range. In all cases, the annealing procedure was carried out with $5^{\circ} \mathrm{C} / \mathrm{min}$ heating rate and $4 \mathrm{~h}$ at annealing temperature. This route of preparation has revealed to be one efficient and cheap technique to obtain high quality nanosized ferrite powder.

\subsection{Measurement setup}

X-ray diffractograms were obtained on a Siemens D5000 apparatus employing $\mathrm{Cu}-\mathrm{K} \alpha$ radiation $(\lambda=1.54056 \AA)$ at $40 \mathrm{kV}$ and $30 \mathrm{~mA}$ with a curved graphite monochromator, an automatic divergence slit (irradiated length $20.00 \mathrm{~mm}$ ), a progressive receiving slit (height $0.05 \mathrm{~mm}$ ), and a flat plane sample holder in a Bragg-Brentano parafocusing optics configuration. Intensity data were collected by the step-counting method (step $0.02 \%$ s). Infrared transmitted spectra were obtained on a FTIR Mattson-7000 spectrometer in the range $\mathbf{2 8 0}-4000 \mathrm{~cm}^{-1}$ with a resolution of $2 \mathrm{~cm}^{-1}$. For this measurement, pellets were prepared by mixing $1 \mathrm{mg}$ of sample with $200 \mathrm{mg}$ of $\mathrm{KBr}$ and compacting with uniaxial press. Raman measurements in the range $100 \mathrm{~cm}-1$ to 1300 $\mathrm{cm}^{-1}$ were carried out with Horiba Jobin Yvon HR-800-UV spectrometer with $532 \mathrm{~nm}$ laser and microscope objective with 50x magnification. 
Magnetic field induced microwave absorption of nickel ferrite nanoparticles has been obtained with the help of an automatic measuring system based on a network analyzer Agilent model E5071C working from 0.1 MHz to 8.5 GHz. Non-magnetic brass sample holder is placed at the end of a copper shorted semi-rigid coaxial line. The powdered sample is pressed into a toroidal shape that completely fills the space between the inner and outer conductors, which are short circuited at the end plane of the sample, ensuring that the sample is located in an area with minimum rf electric field and maximum rf magnetic field. The sample holder is placed into the polar pieces of an electromagnet which produce magnetic fields up to $600 \mathrm{mT}$ with a bipolar DC power supply Kepco BOP 50-8M, The magnetic field in the sample is measured with a gaussmeter FWBell 6010 with a calibrated perpendicular Hall probe. All the system is automated and controlled by using an Agilent VEE control program. Microwave absorption is obtained with the reflected rf signal of $10 \mathrm{dBm}$ sent by analyser, by means of $\mathrm{S}_{11}$ parameter, after translating the measurement plane to the sample position, and subtracting the signal obtained with the empty sample holder, so that we get only the magnetic field induced absorption produced in the sample in the whole frequency range analyzed. This setup allow the broadband measurement of microwave absorption and hence the ferromagnetic resonance (FMR) with varying continuously both the operating frequency and DC magnetic field. [15]. In addition, this measurement setup also allows the measurement of permittivity and permeability of small amounts of magnetic materials in the above referenced frequency range with only the $S_{11}$ parameter [16].

\section{Results and Discussion}

\subsection{Phase identification and structural analysis}


In the Figure 1 we can see that single phase spinel ferrite $[\mathbf{1 7 , 1 8}]$ is obtained for all the annealing temperatures analyzed, except for the as-prepared powder. The average grain diameter has been obtained from them by using the Scherrer's formula (see Table I). Sample particle size increase with annealing temperature in good agreement with the increase in the sharpness of diffraction lines, related to the effect of annealing temperature on the higher crystallinity of the sample. These values are similar to the findings by other authors $[19,20]$. Lithium ferrite is known to occur in two crystalline forms. There is a disordered inverse spinel structure $\left(\beta-\mathrm{LiFe}_{5} \mathrm{O}_{8}\right)$ in which the metallic cations are randomly distributed among the octahedral sites. On the other hand, in the ordered structure $\left(\alpha-\mathrm{LiFe}_{5} \mathrm{O}_{8}\right)$ there is a 1:3 ordering of $\mathrm{Li}$ and Fe cations at the octahedral sites. The ordered structure can be detected by the appearance of superlattice [110] [210] and [211] reflections in the XRD pattern $[17,18]$. As we can see in Fig 1 , these additional superlattice peaks emerge at $2 \theta$ $=15^{\circ}, 24^{\circ}$ and $26^{\circ}$ with increasing annealing temperature ([310] superlattice peak not indexed in the figure seems to appear at $33^{\circ}$ in some samples), thus suggesting the formation of ordered $\alpha$ lithium ferrite with this fabrication route.

Infrared spectroscopy can give information of the local symmetry in crystalline solids, as well as their cationic ordering. In spinel ferrites, up to four broad active bands can be observed: the band located at $560-630 \mathrm{~cm}^{-1}\left(v_{1}\right)$ is attributed to stretching vibrations of the octahedral groups, the band $v 2$ at $390-525 \mathrm{~cm}^{-1}$ is connected to trivalent cations in both octahedral and tetrahedral sites, being usually splitted [21]. The $v_{3}$ band at 335-380 $\mathrm{cm}^{-1}$ is related also to complex vibrations involving tetrahedral and octahedral sites of both divalent and trivalent cations and thus dependent on $\mathrm{Fe}^{2+}$ concentration, and the far infrared band $v_{4}$ observed in $170-255 \mathrm{~cm}^{-1}$ (out of our spectrometer range) is 
assigned to tetrahedral lattice [7, 21]. The 1:3 ordering of Li: Fe cations in octahedral sites along [110] direction reduces the space group from $\mathrm{Fd} 3 \mathrm{~m}$ to $\mathrm{P} 4{ }_{1} 32$, allowing a higher number of active vibration modes regarding the disordered ferrite, in which the $\mathrm{Li}$ and $\mathrm{Fe}$ cations are distributed randomly on octahedral sites, so that splitting of absorption bands is characteristic of ordered lithium ferrite $\alpha-\mathrm{LiFe}_{5} \mathrm{O}_{8}$ [22]. In the Figure 2 we present FTIR spectra of the annealed samples in the range 280 to $1000 \mathrm{~cm}^{-1}$ (the bands among 1300 and $3800 \mathrm{~cm}^{-1}$ vanish due to complete evaporation of nitrates and citrates when the annealing temperature is increased over $400^{\circ} \mathrm{C}$ ). In this range we can observe three active bands at 395,468 , and $580 \mathrm{~cm}^{-1}$, with subsidiary absorptions at 440, 547, 670 and $708 \mathrm{~cm}^{-1}$. They remain almost unchanged with the different annealing temperatures as a clear indicative of a single phase with unchanged lattice parameter [19], and the frequencies agree very well with the results obtained for other authors in $\alpha-\mathrm{LiFe}_{5} \mathrm{O}_{8}$ ordered lithium ferrite $[7,9,19,22]$. The band observed at $330 \mathrm{~cm}^{-1}$ is indicative of the presence of a small amount of $\mathrm{Fe}^{2+}$ in the samples, which produce splitting in the absorption band $v_{3}$ due to Jahn-Teller distortion in the crystal field potential in the octahedral sites.

Raman spectroscopy is a technique very sensitive to structural disorder. In spinel ferrites group theory predicts five active Raman modes related to vibrations of metal cations and oxygen with different frequencies depending of octahedral or tetrahedral coordination, with three of them frequently observed. In addition, cation ordering promotes the activation of additional vibration modes [23]. Like IR results, Raman spectra obtained for our annealed samples are very similar (Figure 3), and we can observe several modes at 200, 234, 260, 300, 321, 357, 377, 396, 439, 462, 485, 546 and $602 \mathrm{~cm}^{-1}$. Enhanced vibrations at 200 and $485 \mathrm{~cm}^{-1}$, and the presence of the bands at 
$260, \mathbf{3 2 1}, \mathbf{3 5 7}, 396,462$ and $546 \mathrm{~cm}^{-1}$ are characteristic of the ordered phase of lithium ferrite $[23,24]$. It is noteworthy that vibration modes of lithium ferrate that appear at $718 \mathrm{~cm}^{-1}$ are absent. After FTIR, Raman, and taking into account the additional [210] and [211] peaks in XRD patterns, we can conclude that our samples are single phase lithium ferrite with ordered structure $\alpha-\mathrm{LiFe}_{5} \mathrm{O}_{8}$.

\subsection{Microwave characterization}

In the Figure 4, magnetic permeability data obtained with an LCR at $1 \mathrm{kHz}$ are presented. We can see how the figures increase with the annealing temperature: asprepared powder at $250{ }^{\circ} \mathrm{C}$ is non-magnetic due to incomplete formation of ferrimagnetic spinel ferrite, samples annealed at $400^{\circ} \mathrm{C}$ to $600^{\circ} \mathrm{C}$ have similar magnetic permeability, whereas samples obtained at $1000^{\circ} \mathrm{C}$ annealing temperature has a higher relative magnetic permeability, regarding the rest of samples. Sample annealed at $800^{\circ}$ C marks the onset of the two different behaviour obtained when annealing at lower or higher temperatures. The results are consistent with the particle sizes, which allow us to conclude that superparamagnetic behaviour is not expected, and for higher annealing temperatures magnetic domain will probably appear. The soft variation with temperature and the absence of local maxima discard the existence of structural or magnetic transitions in each sample, so that we can expect a ferrimagnetic behaviour in all of them in the temperature range analysed.

As a reference of the broadband nature of experimental results, we show in the Figure 5 3D plot of the magnetic induced microwave absorption. This information can also be displayed with 2D colour or contour maps, so that we can observe the overall response of the material. In order to ascertain the magnetic response it is advisable to plot the 
magnetoabsorption as a function of frequency at fixed magnetic fields, as well as the FMR curves of absorption or its derivative as a function of applied magnetic field at a fixed frequency. In this case we can analyse the frequency evolution of resonant field and also the linewidth.

In the Figure 6 the results of microwave magnetoabsorption curves of the different thermally annealed lithium ferrites are shown. Sample without annealing do not exhibit microwave absorption, according to its uncomplete formation. To allow best viewing, we only present a discrete set of figures corresponding to selected values of applied magnetic field. In all the curves we observe a single peak of maximum absorption that shifts to higher frequencies with increasing the applied magnetic field. In the frequency range available with our measurement setup, we can observe the absorption peaks at applied fields up to $150 \mathrm{mT}$. Higher fields shift the peak to frequencies beyond the capability of our network analyser. It is also noteworthy the existence of resonance without applied magnetic field, indicating the existence of an intrinsic anisotropy field of a similar magnitude order that the magnetic fields applied in our experimental setup. It can also be observed that the peaks are very broad in frequency (up to $5.7 \mathrm{GHz}$ full width at half maximum in sample sintered at $600^{\circ} \mathrm{C}$ ), so that they could be good candidates to microwave absorbers in the $\mathrm{C}$ band, with the possibility of tuning the frequency and amount of microwave absorption with annealing temperature and DC magnetic field.

Concerning the strength of microwave absorption, we can also observe the increment of absorbed power with the annealing temperature. Samples prepared at $400-600^{\circ} \mathrm{C}$ behave in a very similar way with figures of about $50 \%$ absorption. Increment in the 
annealing temperature to $800^{\circ} \mathrm{C}$ produce an increase in the absorption up to $80 \%$, and finally the absorption decreases at the higher annealing temperature analysed, in which the effect of applied field is not as preponderant as in the rest of the samples. In addition, the absorption curve is clearly distorted. In this way, sample annealed at 1000 ${ }^{\circ} \mathrm{C}$ differs from the others analysed, so that we can point to the possibility that sample annealed at $1000^{\circ} \mathrm{C}$ contains multiple magnetic domains. This fact is supported for the higher initial permeability (Fig 4) as well as the average crystallite size (700 nm), and has been also observed in other magnetic nanoparticle systems [15].

The results shown in this work are similar to previous ones obtained by us and other authors $[15,25]$, and are related to ferromagnetic resonance of the spinel ferrite. In order to extract the resonance parameters, we can represent the dependence of microwave absorption with the DC applied magnetic field. In our experimental setup, we obtain the reflection coefficient, so that we get the absorbed power. In the Figure 7 we show the computed derivative of absorbed power for sample annealed at $400^{\circ} \mathrm{C}$, at different frequencies. With this type of representation we can obtain the resonance field, the linewidth and in our broadband equipment their frequency dependence (we have intentionally changed $\mathrm{H}$ to cgs units to allow comparison with literature data). The high frequency edge of the resonance is broader and exhibits a lower intensity than the initial one. The inhomogeneous broadening behaviour is common in nanoparticle systems [26, 27] due to the existence of higher order spin-wave modes, that can be originated from different ways: interaggregate dipolar interaction due to large residual strains, porosity or inhomogeneities in the sample, random distributions of anisotropy axis [25], as well as increased losses caused by hopping of conduction electrons that enhances the relaxation, when the particle size is small compared with the skin depth [27]. In the 
Figure $8 \mathrm{a}$, we show the broadening factor calculated as the ratio among minimum and maximum in the derivative of the absorption curve. This calculation is similar to the asymmetry in the absorption curve employed by other authors [28]. We can observe a near linear diminution with the frequency suggesting the effect of variation of conductivity with different skin depth, and the signature of a noteworthy anisotropy. The damping of resonance can be obtained with the frequency evolution of linewidth. In the case of non-interacting particles the damping is characterized by the Gilbert parameter resulting in a linear increase of linewidth with frequency [18]. The frequency evolution of linewidth in the sample annealed at $400{ }^{\circ} \mathrm{C}$, represented in Figure $8 \mathrm{~b}$, do not show a clear increase of linewidth with frequency. This result is also common in nanoparticle systems $[29,30]$. A tentative calculation of damping parameter results values around 0.2 , similar to previous findings and taking into account that for nanoparticles the damping parameter can exceed the bulk value one order of magnitude [30]. We can conclude that rather than Gilbert damping there are extrinsic relaxation mechanisms predominant in this case, as a strong interparticle interaction caused by nanoparticle aggregation, so that apart from dipolar interactions appear intracluster exchange, which leads to the observed deformed resonance curve [31, 32]. The values of linewidth are around 700 Oe that means that, unless is clearly higher than obtained in single crystals [18], is lower than obtained for other authors in similar nanoparticle systems $[27,29,30]$, so that the fabrication method produce particles with lower magnetic inhomogeneity.

Deeper insights will be gained with the resonance field. In order to obtain this characteristic parameter of FMR, the resonance frequency as a function of the magnetic applied field is represented in the Figure 9. We can observe a near linear dependence of 
$\mathrm{H}_{\mathrm{r}}$ with frequency, so that we can fit the data to the Kittel expression for FMR in spheres:

$f_{r}=\frac{g \cdot \gamma}{2 \pi \mu_{0}} \cdot\left(H_{r}+H_{A}\right)$

with $\mathrm{f}_{\mathrm{r}}$ the resonance frequency, $\mathrm{H}_{\mathrm{r}}$ the field at resonance, $\mathrm{g}$ is the spectroscopic splitting factor, $\gamma$ is the gyromagnetic ratio, and $\mathrm{H}_{\mathrm{A}}$ the effective anisotropy field. As we mention above, in this frequency range, the anisotropy field cannot be ignored, as it is similar, or even higher, than the applied magnetic field. With the fitting procedure we obtain gvalues in the $1.95-2.05$ range (i.e. $2.728-2.8680 \mathrm{GHz} / \mathrm{kOe}$ ), close to the $2.139-2.158$ values found in literature data for bulk ferrites [33, 34] and 1.97 for single crystals [18]. The calculated effective anisotropy fields grow from $1.02 \mathrm{kOe}$ for sample annealed at $400^{\circ} \mathrm{C}$ to $1.42 \mathrm{KOe}$ and $1.94 \mathrm{KOe}$ for samples annealed at $600^{\circ} \mathrm{C}$ and $800^{\circ} \mathrm{C}$, then is reduced to $1.84 \mathrm{KOe}$ for the sample annealed at $1000^{\circ} \mathrm{C}$, in very good agreement with the figures obtained previously in Li ferrite films [34] and also similar for other nanoparticulate spinel ferrite systems $[14,15]$, but three to four times higher than bulk Li ferrites [35]. Again the sample annealed at $1000^{\circ} \mathrm{C}$ behaves in a different way that the rest: thermal annealing enhance crystallite growth and promotes multidomain structure which allow spin as well as domain wall resonance, thus broadening and distorting the resonance line at lower frequencies.

The anisotropy field is directly related to the anisotropy constant of the material. To obtain this parameter, we have measured the magnetic parameters of the sample annealed at $1000{ }^{\circ} \mathrm{C}$, obtaining a saturation magnetization of $52.7 \mathrm{emu} / \mathrm{g}$ and a coercive field of 50 Oe at room temperature. Even with the maximum annealing temperature, saturation magnetization is lower than bulk magnetization. This fact is clearly indicative that we are dealing with a core-shell assembly of interacting particles in which each 
particle is composed by a core with collinear ferrimagnetic order surrounded by a surface or shell with some degree of spin disordering. With simple calculations [36] it is possible to estimate roughly the shell thickness, obtaining around $9 \mathrm{~nm}$, that correspond to 6 lattice steps. With the measured $\mathrm{M}_{\mathrm{S}}$ and the obtained anisotropy field after FMR fitting, we can calculate the value of the effective anisotropy constant, to get $2.4 \cdot 10^{4}$ $\pm 0.43 \cdot 10^{4} \mathrm{~J} / \mathrm{m}^{3}$. This value is three times higher than the magnetocrystalline anisotropy value of $0.9 \cdot 10^{4} \mathrm{~J} / \mathrm{m}^{3}$ reported for bulk lithium ferrites. It is noteworthy that for magnetic nanoparticles, the value of the effective anisotropy constant is determined not only by the contribution of the bulk magnetocrystalline anisotropy, but also by the surface, strain and/or shape anisotropy, as well as the anisotropy arising from interparticle interactions, that account for the increase of effective anisotropy, and in our case the value obtained is close to the value of $4 \cdot 10^{4} \mathrm{~J} / \mathrm{m}^{3}$ obtained with a different measurement approach by Yang in a very similar ferrite system [20] assuming a coreshell configuration of the nanoparticles annealed at lower temperatures, and multidomain behaviour in the higher size particles, in a similar way as our findings. For smaller particles, the higher surface to volume ratio will make the effect of the shell even more relevant, in which the broken bonds produce a different chemical and exchange effect than in the core. Spin canting lead to equivalent canted states, and relaxation among these two states cause line broadening. In addition, in this ferrite system it is known that some Li displacement takes place from the core to the shell [37], so that the increased amount of inhomogeneities in the shell further broaden the resonance regarding bulk and single crystals.

\section{Conclusions}


Magnetic field induced microwave absorption at frequencies up to $8.5 \mathrm{GHz}$ have been measured in different thermally annealed Li ferrite nanoparticles obtained with sol-gel Pechini method. The results agree well with the theory of ferromagnetic resonance. The wide microwave absorption observed reveals that this material can be used as absorber in the $\mathrm{C}$ band with the possibility of tuning the frequency and amount of microwave absorption with annealing temperature and DC magnetic field. The fabrication method employed produces particles with ordered cation distribution in octahedral sites, and lower magnetic inhomogeneity regarding the FMR linewidth. Nanoparticle Li ferrites have higher effective anisotropy fields than bulk ferrites, and also broader linewidths due to the disordered surface spins.

\section{Acknowledgements}

Funding: This work was supported by the Spanish Ministerio de Economía, Industria y Competitividad (AEI with FEDER) project id. MAT2016-80784-P

\section{References}

[1] V.A.M. Brabers, Progress in spinel ferrite research, in K.H.J. Buschow (ed) Handbook of ferromagnetic materials vol 8, Elsevier Science 1995.

[2] J. Nicolas, Microwave ferrites, in E. P. Wolfarth (ed), Ferromagnetic materials North Holland Publ. 1980.

[3] G. O. White, C. E. Patton, Magnetic properties of lithium ferrite microwave materials, J. Magn. Magn. Mater. 9 (1978) 299-317.

[4] P. Baba, G. Argentina, W. Courtney, G. Dionne, D. Temme, Fabrication and properties of microwave lithium ferrites, IEEE Trans Magn. 8(1) (1972) 83-94. 
[5] M. Pardavi-Horvath, Microwave applications of soft ferrites, J. Magn. Magn. Mater. 215-216 (2000) 171-183.

[6] V. G. Harris, A. Geiler, Y. Chen, S. D. Yoon, M. Wu, A. Yang, Z. Chen, P. He, P. V. Parimi, X. Zuo, C. E. Patton, M. Abe, O. Acher, C. Vittoria, J. Magn. Magn. Mater. $321(2009) 2035$.

[7] E. Wolska, P. Piszora, W. Nowicki, J. Darul, Vibrational spectra of lithium ferrites: infrared spectroscopic studies of Mn-substituted $\mathrm{LiFe}_{5} \mathrm{O}_{8}$, Int. J. Inorg. Mater. 3 (2001) 503-507.

[8] G. Bonsdorf, H. Langbein, K. Knese, Investigations into phase formation of $\mathrm{LiFe}_{5} \mathrm{O}_{8}$ from decomposed freeze-dried Li-Fe-formates, Mater. Res Bull. 30(2) (1995) 175-181. [9] V. K. Sankaranarayanan, Q. A. Pankhurst, D. P. E. Dickson, C. E. Johnson, Synthesis and characterization of ultrafine lithium ferrite from a citrate precursor, J. Magn. Magn. Mater. 130 (1994) 288-292.

[10] M. Abdullah Dar, J. Shah, W. A. Siddiqui, R. K. Kotnala, Influence of synthesis approach on structural and magnetic properties of lithium ferrite nanoparticles, J. All. Comp. 523, (2012) 36-42.

[11] B. R. Elbert, Introduction to Satellite Communication, $3^{\text {rd }}$ Ed. Artech House, Boston-London, 2008.

[12] V. Sharma, B. K. Kuani, Magnetic and crystallographic properties of rare-earth substituted yttrium-iron-garnet. J. All Comp. 748 (2018) 591-600.

[13] M. Yoshikiyo, A. Namai, S. Ohkoshi, Unusual Temperature Dependence of ZeroField Ferromagnetic Resonance in Millimeter Wave Region on Al-Substituted $\varepsilon-\mathrm{Fe}_{2} \mathrm{O}_{3}$, in Orhan Yalcin (Ed) Ferromagnetic Resonance - Theory and Applications,: InTech Publ, 
[14] G.V. Kurlyandskaya, S.M. Bhagat, C. Luna and M. Vazquez, Microwave absorption of nanoscale CoNi powders, J. Appl. Phys. 99 (2006) 104308.

[15] P. Hernández-Gómez, J. M. Muñoz, M. A. Valente, Field-Induced Microwave Absorption in Ni Ferrite Nanoparticles, IEEE Trans Magn. 46(2) (2010) 475-478.

[16] D. González-Herrero, J. M. Muñoz, C. Torres, P. Hernández-Gómez, Ó. Alejos, C. de Francisco, A new method to measure permittivity and permeability in nanopowder materials in microwave range, Appl. Phys. A 112(3) (2013)719-725.

[17] S. Verma, P. A. Joy, Magnetic properties of superparamagnetic lithium ferrite nanoparticles, J. Appl. Phys. 98 (2005) 124312.

[18] N. Pachauri, B. Khodadad, M. Althammer, A. Singh, L. Boddapati, R. Datta, M. Iliev, L. Bezmaternykh, I. Gudim, T. Mewes, A. Gupta, Study of structural and ferromagnetic resonance properties of spinel lithium ferrite $\left(\mathrm{LiFe}_{5} \mathrm{O}_{8}\right)$ single crystals, $\mathrm{J}$. Appl. Phys. 117 (2015) 233907.

[19] W.R. Agami, M.A. Ashmawy, A.A. Sattar, Structural, IR, and magnetic studies of annealed Li-ferrite nanoparticles, J. Materials Engineering and Performance, 23(2) (2014) 604-610.

[20] H. Yang, Z. Wang, L. Song, M. Zhao, J. Wang and H. Luo. A study on the coercivity and the magnetic anisotropy of the lithium ferrite nanocrystallite, J. Phys. D: Appl. Phys. 29 (1996) 2574-2578.

[21] G. C. Allen, M. Paul, Chemical characterization of transition metal spinel-type oxides by infrared spectroscopy, Appl. Spectrosc. 49(4) (1995) 451-458.

[22] S. A. Mazen, F. Metawe, S. F. Mansouri, IR absorption and dielectric properties of Li-Ti ferrite, J. Phys. D: Appl. Phys. 30 (1997) 1799-1808. 
[23] C. M. Julien, F. Gendron, A. Amdouni, M. Massot, Lattice vibrations of materials for lithium rechargeable batteris. VI. Ordered spinels, Mat. Sci. Eng B, 130 (2006) 4148.

[24] W. Cook, M. Manley, Raman characterization of $\alpha$ - and $\beta-\mathrm{LiFe}_{5} \mathrm{O}_{8}$ prepared through a solid-state reaction pathway, J. Sol. State Chem. 183(2) (2010) 322-326. [25] R. Valenzuela, F. Herbst, S. Ammar, Ferromagnetic resonance in Ni-Zn ferrite nanoparticles in different aggregation states, J. Magn. Magn. Mater. 324 (2012) 33983401 .

[26] R. Diaz-Pardo, R. Valenzuela, Characterization of magnetic phases in nanostructured ferrites by electron spin resonance, in Saad Osman Bashir (ed) Advanced Electromagnetic Waves, IntechOpen 2015.

[27] E.K. Al-Shakarchi, S.H. Lafta, A. Musa, M. Farle, R. Salikhov, The FMR behaviour of Li-Ni ferrite prepared by hydrothermal method. J Supercond Nov Magn 30 (2017) 2575-2579.

[28] A. Iglesias, I. V. Guerasimenko, S.Díaz Castañón, Arnaldo González Arias , Nonstoichiometric LiZnTi ferrites for microwave applications, physica status solidi (a) 140(1):221-226.

[29] S. Keshavarz, Y. Xu, S. Hrdy, C. Lemley, T. Mewes, Y. Bao, Relaxation of polymer coated $\mathrm{Fe}_{3} \mathrm{O}_{4}$ magnetic nanoparticles in aqueous solution, IEEE Trans Magn 46(6) (2010)1541-1543.

[30] V. Castel, J. Ben Youssef, C. Brosseau, Broadband ferromagnetic resonance measurements in $\mathrm{Ni} / \mathrm{ZnO}$ and $\mathrm{Niy}-\mathrm{Fe}_{2} \mathrm{O}_{3}$ nanocomposites J. Nanomaterials 2007 (2007) 27437. 
[31] F. Gazeau, J. C. Bacri, F. Gendron, R. Perzynski, Yu. L. Raikher, V. I. Stepanov, E. Dubois, Magnetic resonance of ferrite nanoparticles:. evidence of surface effects, J. Magn. Magn. Mater 186(1-2), (1998) 175-187.

[32] A. Sukhov, K. D. Usadel, U. Nowak, Ferromagnetic resonance in an ensemble of nanoparticles with randomly distributed anisotropy axes, J. Magn. Magn. Mater. 320 (2008) 31-35.

[33] W. H. von Aulock, Handbook of Microwave Ferrite Materials, ed. Academic Press,New York, 1965, p. 407

[34] F. J. Cadieu, R. Rani, W. Mendoza, B. Peng, S. A. Shaheen, M. J. Hurben, and C. E. Patton, J. Appl. Phys. 81, 4801 (1997)

[35] C. J. Brower and C. E. Patton, Determination of anisotropy field in polycrystalline lithium ferrites from FMR linewidths, J. Appl. Phys. 53 (1982) 2104.

[36] N. Jovic, B. Antic, G. F., Goya, V. Spasojevic, Magnetic properties of lithium ferrite nanoparticles with a core/shell structure, Current Nanoscience 2012, 8 [37] N. G. Jović, A. S. Masadeh, A. S. Kremenović, B. V. Antić, J. L. Blanuša, N. D. Cvjetičanin, G. F. Goya, M. V. Antisari and E. S. Božin, Effects of Thermal Annealing on Structural and Magnetic Properties of Lithium Ferrite Nanoparticles, J. Phys. Chem. C 113 (48) (2009) 20559. 


\section{Figure and Table Captions}

Figure 1. X ray diffractograms of the as prepared at $250^{\circ} \mathrm{C}$ and annealed Li ferrite samples at $400^{\circ} \mathrm{C}, 600^{\circ} \mathrm{C}, 800^{\circ} \mathrm{C}$, and $1000^{\circ} \mathrm{C}$.

Figure 2. FTIR spectra of the annealed Li ferrite nanoparticle samples at $400^{\circ} \mathrm{C}, 600^{\circ}$ $\mathrm{C}, 800^{\circ} \mathrm{C}$, and $1000^{\circ} \mathrm{C}$.

Figure 3. Raman scattering spectra of the Li ferrite nanoparticle sample annealed at $800^{\circ} \mathrm{C}$

Figure 4. Initial magnetic permeability of the as prepared and annealed Li ferrite nanoparticles.

Figure 5. 3D plot of magnetoabsorption vs applied magnetic field and frequency corresponding to sample annealed at $400^{\circ} \mathrm{C}$.

Figure 6. Microwave absorption as a function of frequency, at different applied magnetic fields (curves shift with increasing applied field from left to right in each graph), corresponding to $\mathrm{LiFe}_{2.5} \mathrm{O}_{4}$ nanoparticle samples annealed at $400^{\circ} \mathrm{C}, 600^{\circ} \mathrm{C}$, $800^{\circ} \mathrm{C}$, and $1000^{\circ} \mathrm{C}$.

Figure 7. FMR of Li ferrite nanoparticles annealed at $400^{\circ} \mathrm{C}$ at different frequencies. Figure 8. a) Broadening factor $\mathrm{R}=(-\mathrm{dP} / \mathrm{dH})_{\min } /(\mathrm{dP} / \mathrm{dH})_{\max }$ variation with frequency in sample annealed at $400^{\circ} \mathrm{C}$. b) Linewidth of ferromagnetic resonance vs frequency. Figure 9. Resonance frequency as a function of magnetic applied field, corresponding to Li ferrite nanoparticles annealed at $400-1000^{\circ} \mathrm{C}$.

Table I. Particle size of the as prepared at $250^{\circ} \mathrm{C}$ and annealed Li ferrite samples at $400^{\circ} \mathrm{C}, 600^{\circ} \mathrm{C}, 800^{\circ} \mathrm{C}$, and $1000^{\circ} \mathrm{C}$. 
Table I. Particle size of the as prepared at $250^{\circ} \mathrm{C}$ and annealed Li ferrite samples at $400^{\circ}$ $\mathrm{C}, 600^{\circ} \mathrm{C}, 800^{\circ} \mathrm{C}$, and $1000^{\circ} \mathrm{C}$.

\begin{tabular}{lc}
\hline $\begin{array}{l}\text { Annealing } \\
\text { temperature }\end{array}$ & $\begin{array}{c}\text { Particle } \\
\text { size }(\mathrm{nm})\end{array}$ \\
\hline $250^{\circ} \mathrm{C}$ & $15 \pm 1$ \\
$400^{\circ} \mathrm{C}$ & $30 \pm 3$ \\
$600^{\circ} \mathrm{C}$ & $50 \pm 8$ \\
$800^{\circ} \mathrm{C}$ & $240 \pm 19$ \\
$1000^{\circ} \mathrm{C}$ & $720 \pm 26$ \\
\hline
\end{tabular}




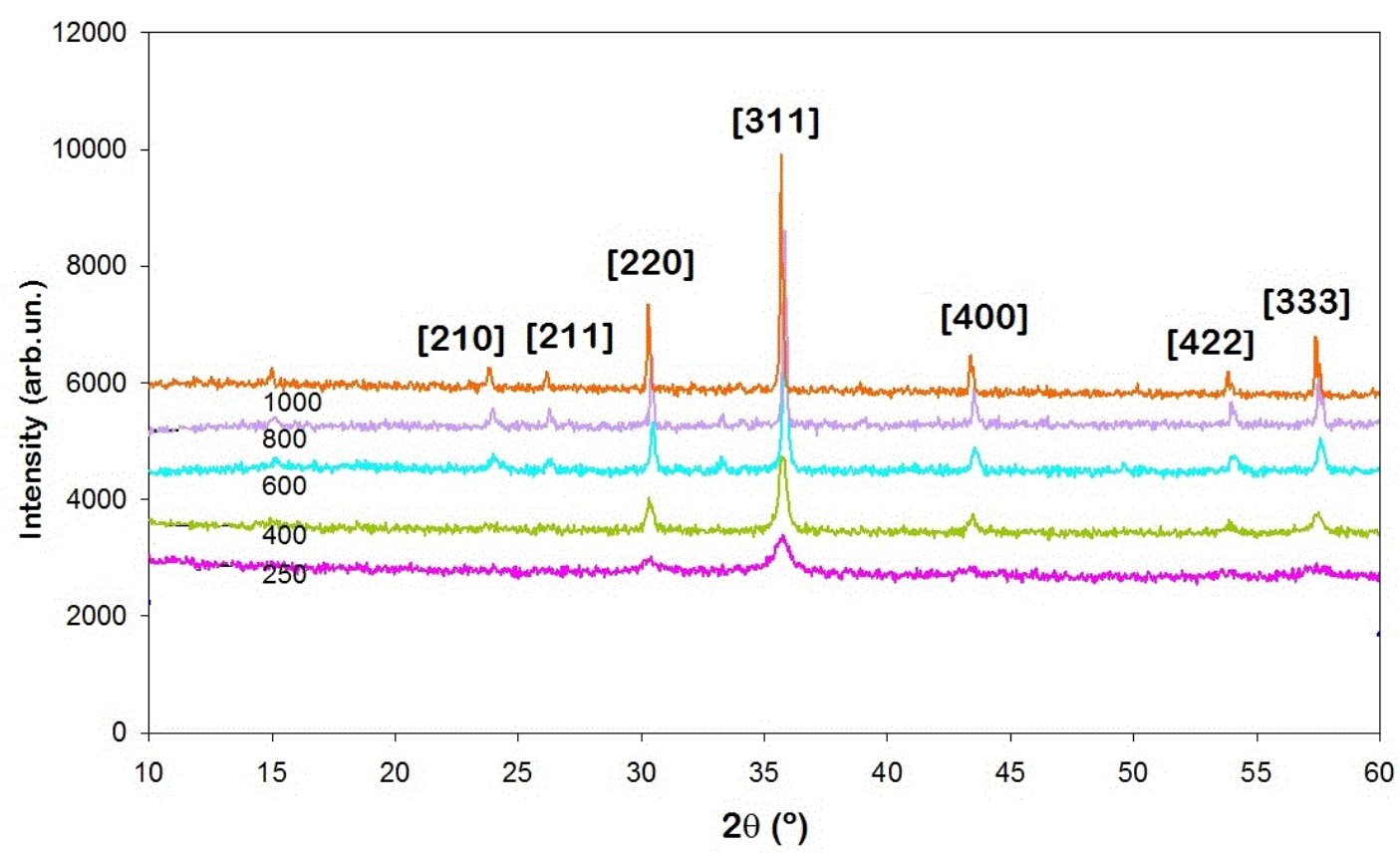

Figure $1 \mathrm{X}$ ray diffractograms of the as prepared at $250^{\circ} \mathrm{C}$ and annealed Li ferrite nanoparticle samples at $400^{\circ} \mathrm{C}, 600^{\circ} \mathrm{C}, 800^{\circ} \mathrm{C}$, and $1000^{\circ} \mathrm{C}$. 


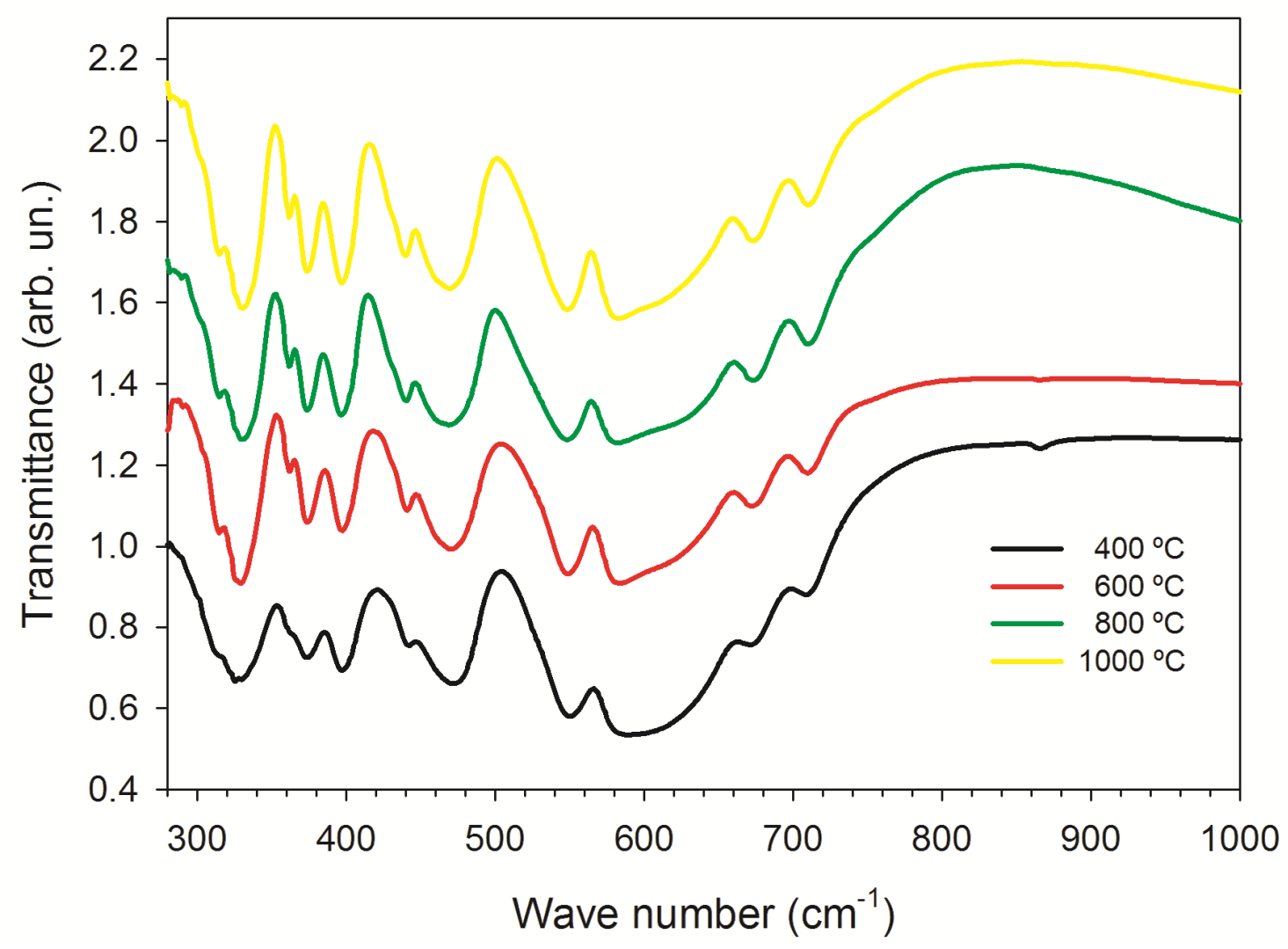

Figure 2 FTIR spectra of the annealed Li ferrite nanoparticle samples at $400^{\circ} \mathrm{C}, 600^{\circ} \mathrm{C}$, $800^{\circ} \mathrm{C}$, and $1000^{\circ} \mathrm{C}$. 


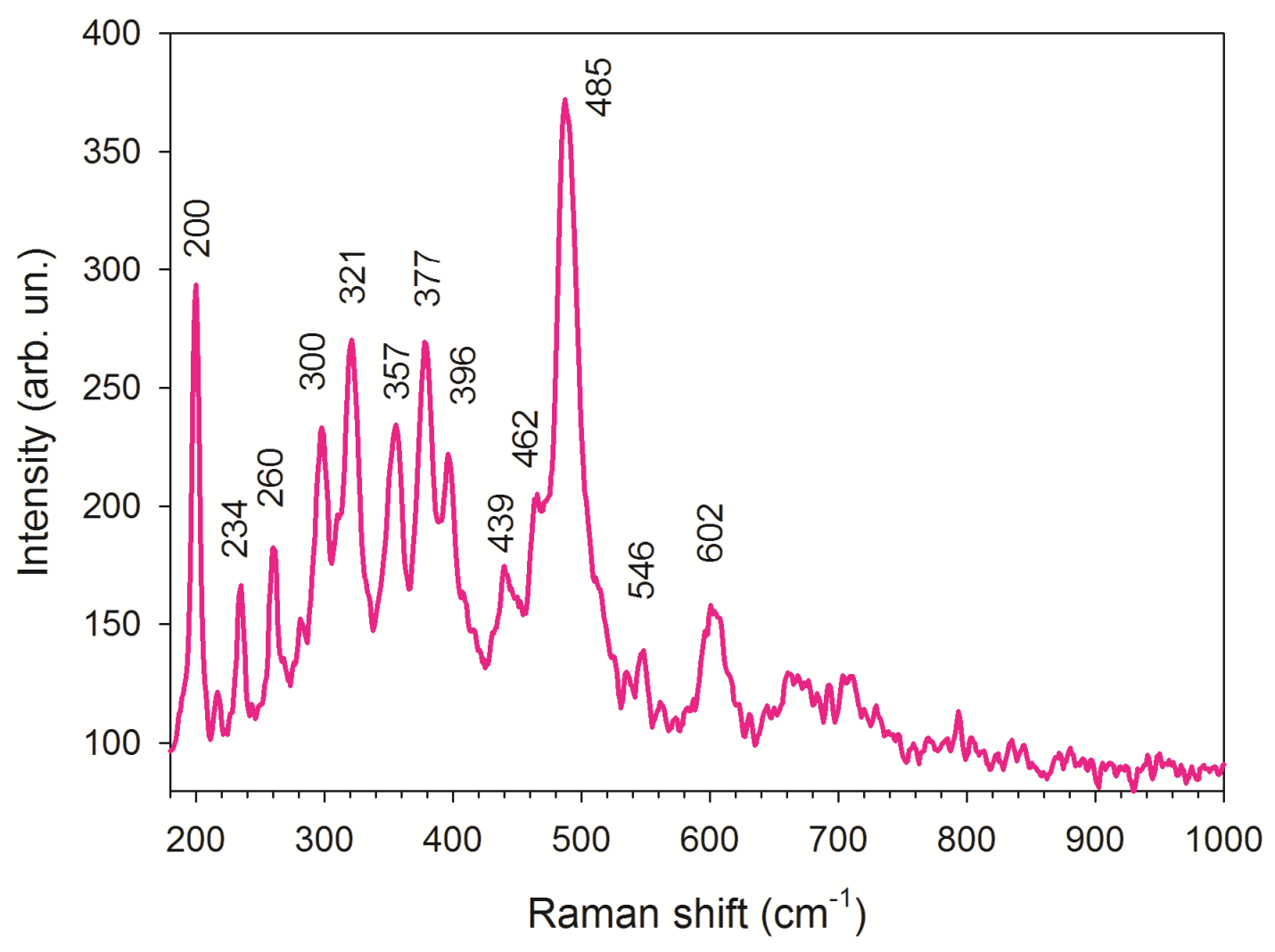

Figure 3. Raman scattering spectra of the Li ferrite nanoparticle sample annealed at $800^{\circ}$ C. 


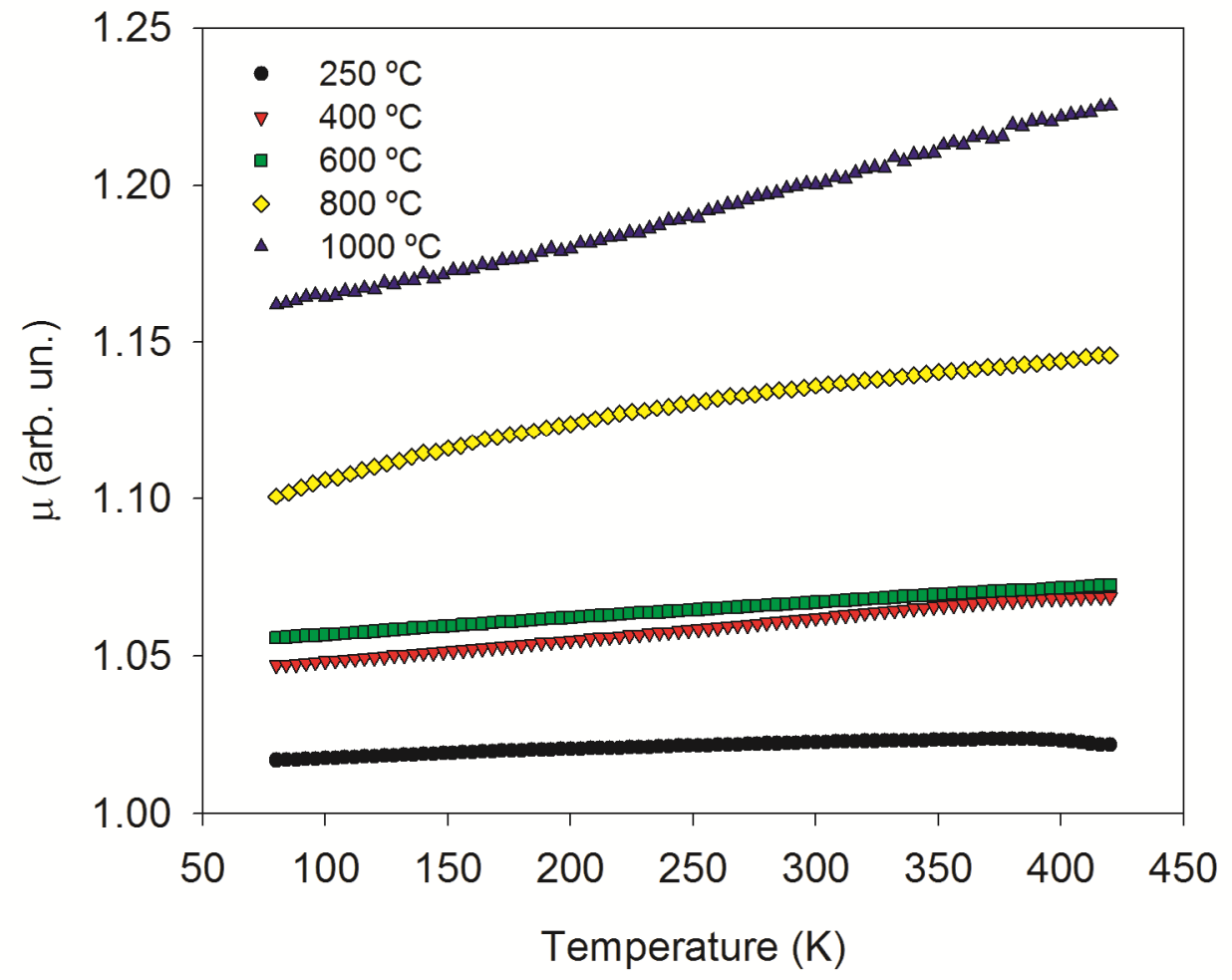

Figure 4. Initial magnetic permeability of the as prepared and annealed Li ferrite nanoparticles. 


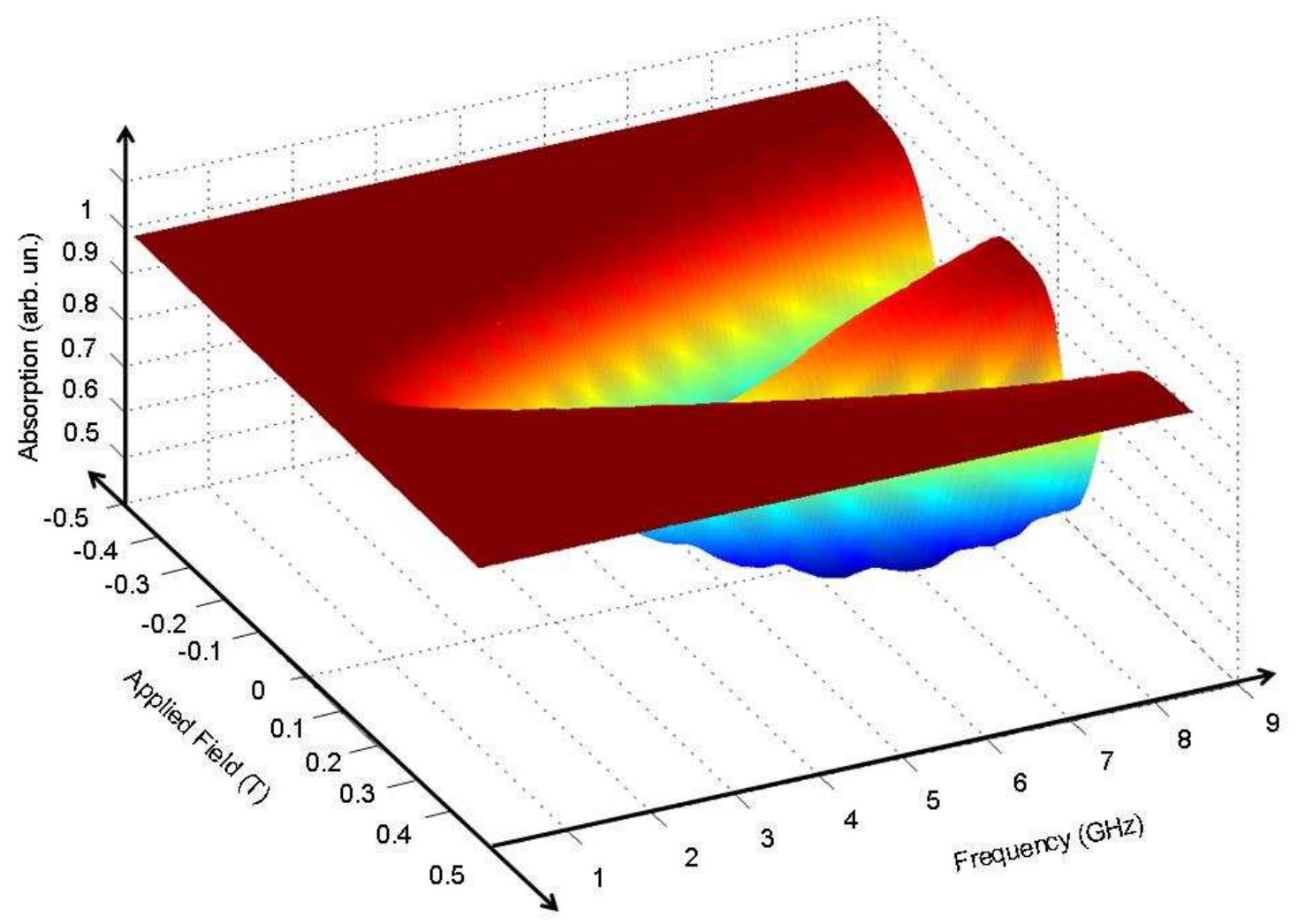

Figure 5. 3D plot of magnetoabsorption vs applied magnetic field and frequency corresponding to sample annealed at $400^{\circ} \mathrm{C}$. 


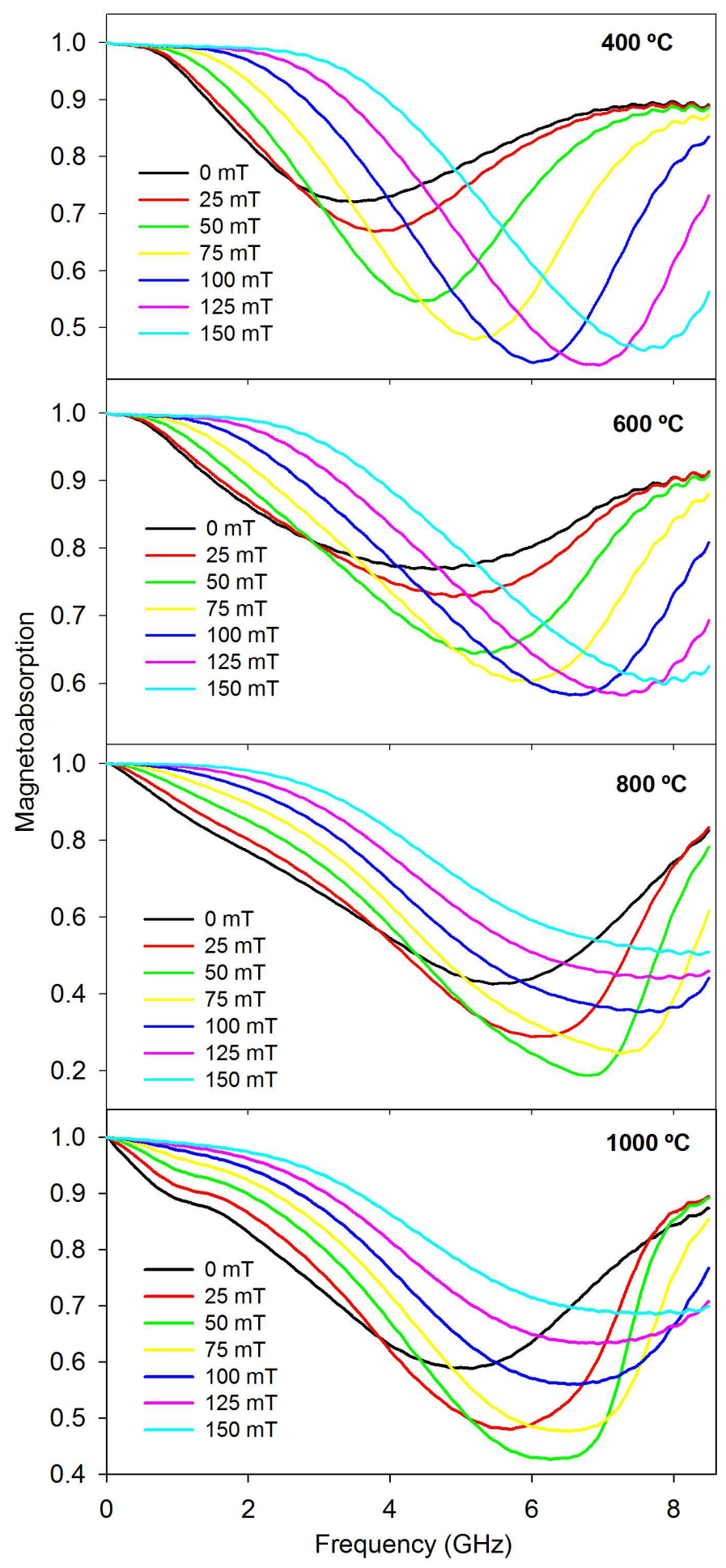

Figure 6 Microwave absorption as a function of frequency, at different applied magnetic fields (curves shift with increasing applied field from left to right in each graph), corresponding to $\mathrm{LiFe}_{2.5} \mathrm{O}_{4}$ nanoparticle samples annealed at $400^{\circ} \mathrm{C}, 600^{\circ} \mathrm{C}, 800^{\circ} \mathrm{C}$, and $1000^{\circ} \mathrm{C}$. 


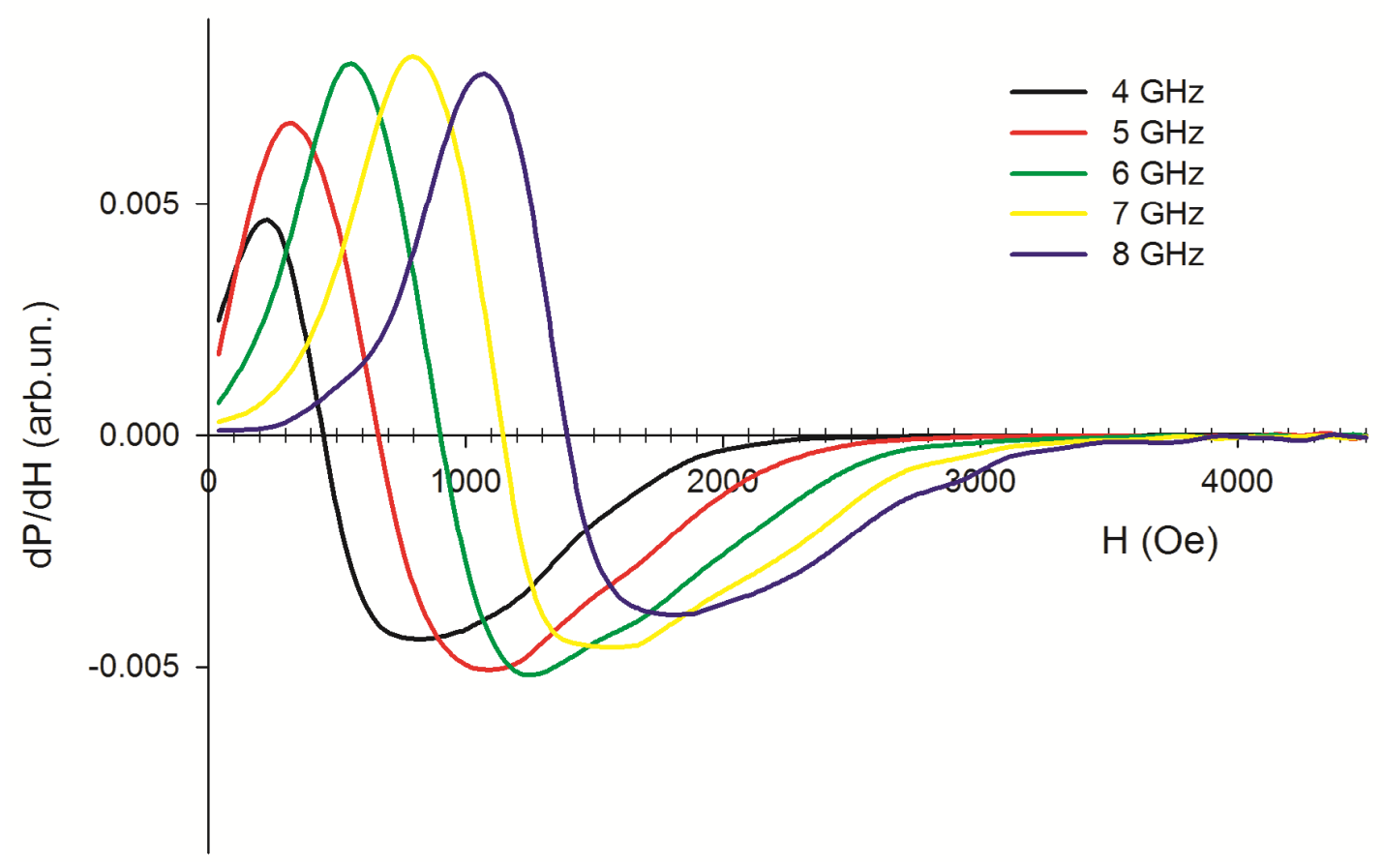

Figure $7 \mathrm{FMR}$ of Li ferrite nanoparticles annealed at $400^{\circ} \mathrm{C}$ at different frequencies. 


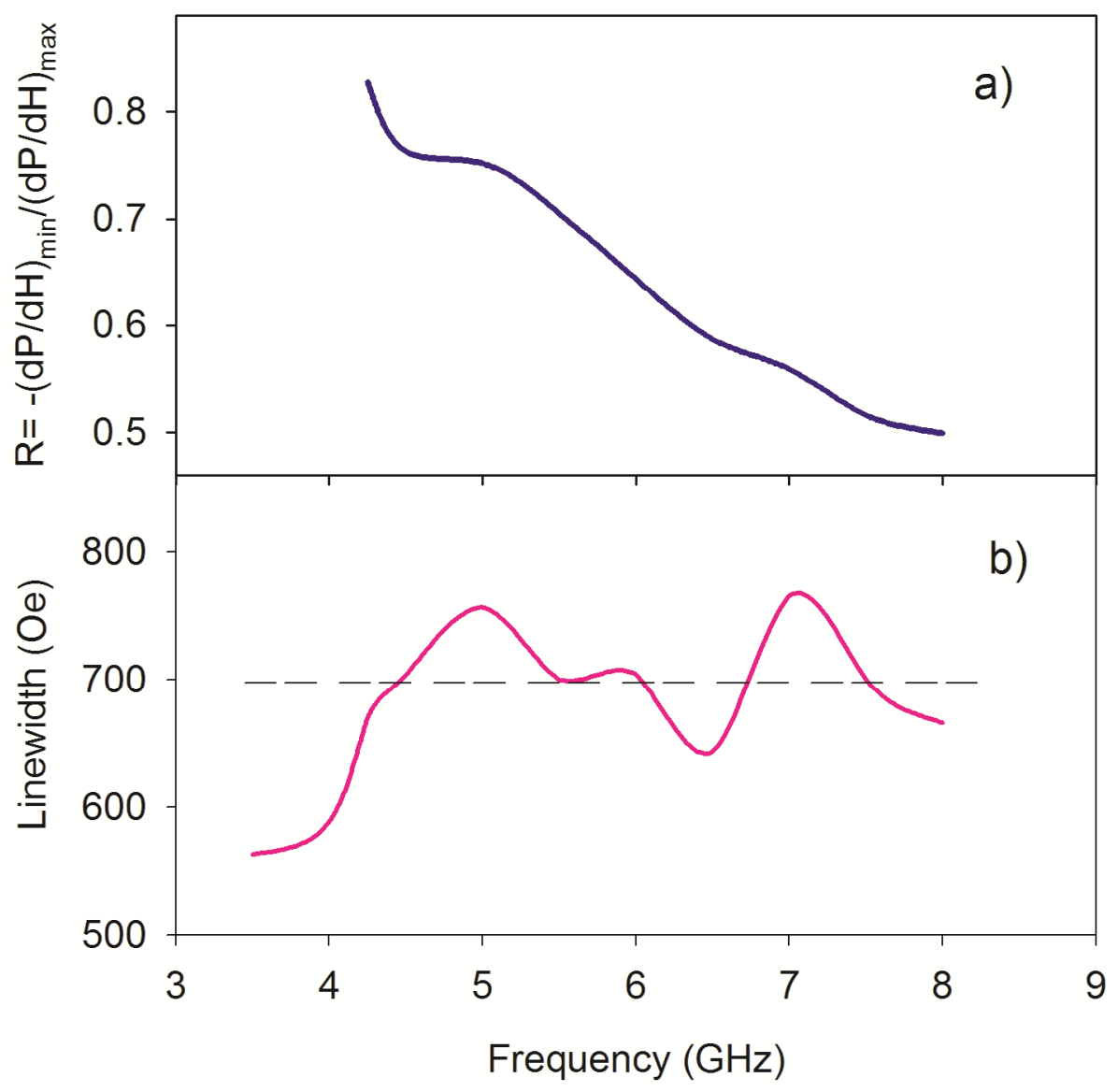

Figure 8. a) Broadening factor $\mathrm{R}=(-\mathrm{dP} / \mathrm{dH})_{\min } /(\mathrm{dP} / \mathrm{dH})_{\max }$ variation with frequency in sample annealed at $400^{\circ} \mathrm{C}$. b) Linewidth of ferromagnetic resonance vs frequency. 


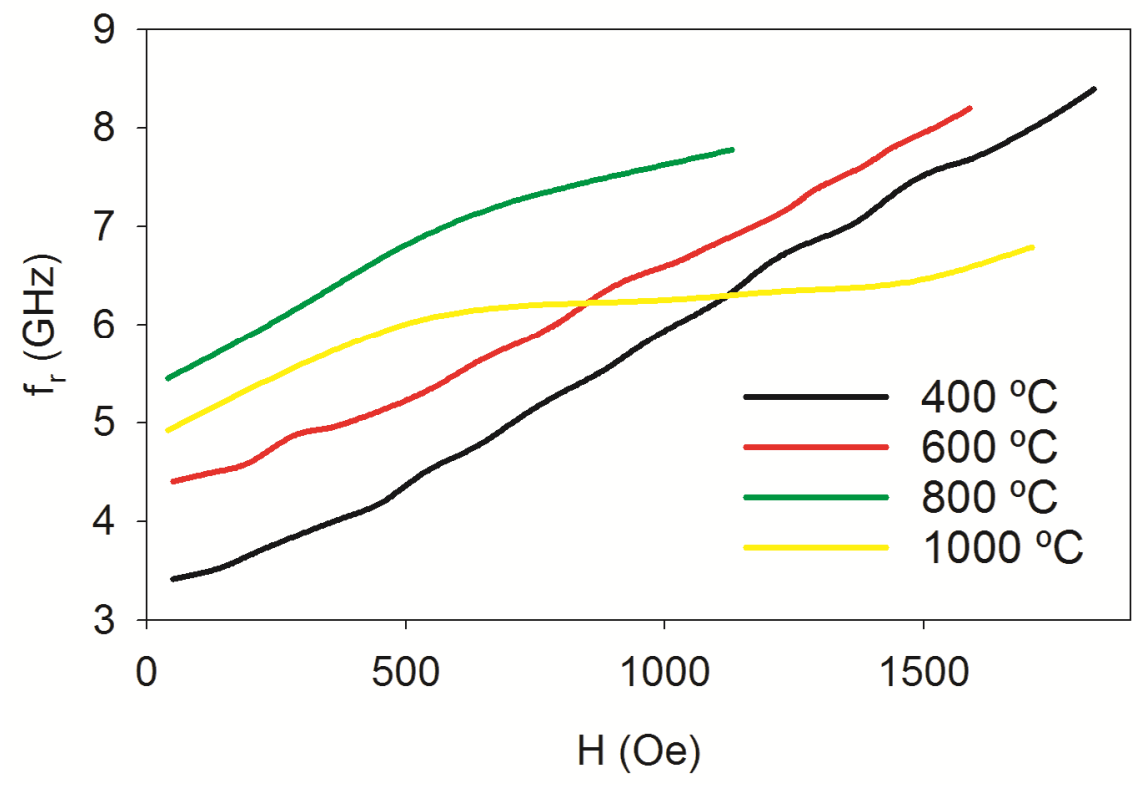

Figure 9. Resonance frequency as a function of magnetic applied field, corresponding to Li ferrite nanoparticles annealed at $400-1000^{\circ} \mathrm{C}$. 